\title{
Clinical and Radiographic Characteristics of the Primary Teeth Indicated For Pulpectomy: A Cross-Sectional Analysis
}

INTRODUCTION: Although difficult to achieve but an accurate diagnosis of pulp status is important for the success of pulp therapy in primary teeth. Clinical signs and symptoms, as well as radiographic characteristics, are important in this regard.

MATERIALS AND METHOD: This cross-sectional analysis evaluated the clinical and radiographic characteristics in 60 decayed primary mandibular second molars from children aged 4-8 years indicated for single visit pulpectomy treatment based on their history, clinical examination and radiographic examination.

RESULTS: Pain was present in $60 \%$ of cases followed by tenderness on percussion (1.7\%) and sinus tract (1.7\%). Evaluation of duration of onset of pulpal involvement revealed $86.7 \%$ cases had chronic involvement whereas $13.3 \%$ cases showed an acute exacerbation of chronic involvement. Irreversible pulpitis was present in $68.3 \%$ cases followed by pulp necrosis in $28.3 \%$. Only 7 out of 60 cases indicated for pulpectomy showed radiographic involvement in periapical or furcation areas.

CONCLUSION: Pain was the most common symptom. Majority of cases had chronic involvement and irreversible pulpitis was the most common indication for pulpectomy followed by pulp necrosis. Only a few cases indicated for pulpectomy in the present study had radiographic involvement present.

KEYWORDS: Clinical and radiographic symptoms, Pulpectomy, Primary teeth

\section{INTRODUCTION}

In spite of the emphasis on prevention, damage to dental pulp from factors such as dental caries, restorative dental treatment \& materials and traumatic injuries etc. cannot be eliminated and premature loss of pulpally involved primary teeth still remains a common problem. Pulpectomy procedure has been recommended for the primary teeth with irreversible pulpal inflammation or necrosis of the radicular pulp. The main objective of the procedure is to effectively remove the infection in infected primary teeth. ${ }^{1}$ The technique involves the removal of irreversibly inflamed or necrotic radicular pulp tissue by cleaning the root canal system, followed by root canal filling with a material that can resorb at the same rate as the primary tooth and be eliminated rapidly if accidentally extruded through the apex. ${ }^{2}$ The success of root canal treatment depends on the method and the quality of instrumentation, irrigation, disinfection, and obturation of the root canals.,

Therefore there is continuous scope to improve and carry out the research in perfecting the procedure and materials aiming at evolving better outcome of root canal treatment in these teeth. Procedures aimed at preventing and treating pulp disease in the primary and immature permanent teeth, therefore, remain an integral part of contemporary dental practice. Successful management of the pulpally involved primary tooth is critical in preserving arch space, preventing aberrant tongue habits and speech problems, maintaining esthetics, preventing the psychological effects associated with early tooth loss and maintaining normal eruption time of the succedaneous teeth. ${ }^{2}$

Although an accurate diagnosis of the pulp status is very important to achieve success in pulp therapy, however, it is difficult to achieve in primary teeth with the pulpal involvement. It is frequently overlooked in the pediatric population. This can adversely affect the treatment plan. Diagnosis should be based on clinical signs and symptoms, their history, diagnostic tests, and radiographic findings. Diagnostic test responses given by patients are subjective and can lead to incorrect result due to their fear and anxiety. ${ }^{5}$ Therefore clinical and radiographic features always remain the mainstay in the diagnosis.

\section{MATERIALS AND METHOD}

This cross-sectional analysis evaluating the clinical and radiographic characteristics in primary mandibular second molars indicated for single visit pulpectomy is based on a randomized control trial carried out for comparative evaluation of manual 
and rotary methods of root canal instrumentation in primary teeth. A total of 6o decayed mandibular second primary molars requiring the pulpectomy treatment based on history, clinical examination and radiographic examination were selected for present study from children aged 4-8 years, attending the outpatient unit of Pediatric and Preventive Dentistry at Oral Health Sciences Centre, PGIMER, Chandigarh. Primary mandibular second molars having necrotic pulp and/or sinus tract and/or irreversible pulpitis and/or radiolucent areas in furcation or periapical region with at least twothirds of each root remaining and sufficient tooth structure to support a rubber dam were included in the present study. Each child included in the study was recorded for personal information, chief complaint, clinical examination, radiographic examination, and other parameters using a specially prepared proforma

Children with mental disabilities, systemic diseases, non-restorable teeth, perforated pulpal floor, abscess, swelling (intraoral or extraoral), excessive mobility and pathological root resorption (internal or external) and those requiring sedation/general anesthesia for management were not included in the study sample. The parents were informed about the objectives and benefits of pulpectomy procedure using manual and rotary instrumentation technique and a written informed consent were taken from the parents regarding the participation of their child in the study. An ethical clearance was obtained from the institutional ethics committee (Intramural) before the commencement of the study.
The selected mandibular second primary molars were randomly allocated to one of the two groups by an independent researcher not involved in the study. The selected teeth had an equal chance of being included in any of the two groups. The two groups comprising the study were Group manualInstrumentation of root canals during pulpectomy procedure using manual stainless steel files and Group rotary-Instrumentation of root canals during pulpectomy procedure using rotary nickel-titanium files. After the preoperative behavior rating of the child, he/she was taken up for root canal treatment performed in a single appointment by the same operator (Principle investigator) for the selected teeth. The endodontic procedural steps in the selected pulpally involved primary molars were the same in the two groups except for the method of root canal instrumentation.

\section{RESULTS}

There was no statistically significant difference between the two study groups in terms of age, gender and type of tooth selected (Table 1). The evaluation of preoperative clinical parameters revealed the pain to be the most common symptom found in $60 \%$ cases (Table 2). On recording the duration of onset of disease it was found that the majority of cases $(86.7 \%)$ had chronic involvement (Table 3). The results also revealed the irreversible pulpitis $(68.3 \%)$ was the most common indication for pulpectomy followed by pulp necrosis (Figure 1). Radiographic evaluation revealed only seven out of 60 cases were involving furcation or periapical areas (Table 4).

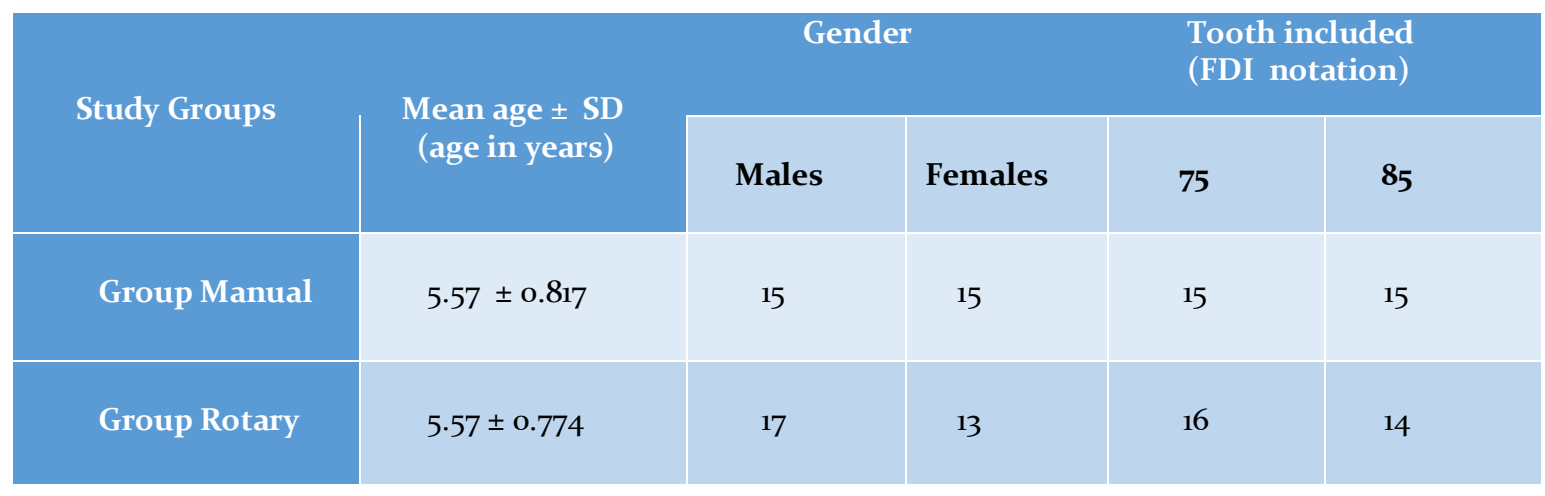

Table 1. Age, Gender and Tooth Wise Distribution of 4-8 Year Children Selected For Pulpectomy 


\begin{tabular}{|c|c|c|c|c|c|c|c|}
\hline \multirow[t]{2}{*}{ Clinical parameters } & \multicolumn{2}{|c|}{$\begin{array}{l}\text { Group Manual } \\
(N=30)\end{array}$} & \multicolumn{2}{|c|}{$\begin{array}{l}\text { Group Rotary } \\
\qquad(\mathrm{N}=30)\end{array}$} & \multicolumn{2}{|c|}{$\begin{array}{c}\text { Total } \\
(\mathrm{N}=60)\end{array}$} & \multirow[b]{2}{*}{ P value } \\
\hline & $\mathbf{N}$ & $\%$ & $\mathbf{N}$ & $\%$ & $\mathbf{N}$ & $\%$ & \\
\hline $\begin{array}{c}\text { No clinical symptoms } \\
\text { at baseline }\end{array}$ & 12 & $40 \%$ & 17 & $36.7 \%$ & 19 & $31.7 \%$ & 0.15 \\
\hline Pain & 18 & $60 \%$ & 18 & $60 \%$ & 36 & $60 \%$ & 1.00 \\
\hline $\begin{array}{c}\text { Tenderness on } \\
\text { percussion }\end{array}$ & o & o & 1 & $3.3 \%$ & 1 & $1.7 \%$ & 0.31 \\
\hline Sinus tract & 1 & $3.3 \%$ & o & o & 1 & $1.7 \%$ & 0.31 \\
\hline Abscess & o & o & o & o & o & o &.$^{\mathrm{a}}$ \\
\hline Mobility & 0 & o & o & 0 & o & o &.$^{\mathrm{a}}$ \\
\hline
\end{tabular}

Table 2. Preoperative Clinical Parameters in the Children Selected For Pulpectomy (Note: .a-Test is not applicable)

\begin{tabular}{|c|c|c|c|c|c|c|c|}
\hline \multirow{3}{*}{ Duration } & \multicolumn{4}{|c|}{ Study groups } & & & \multirow{3}{*}{ P value } \\
\hline & \multicolumn{2}{|c|}{$\begin{array}{l}\text { Group manual } \\
\qquad(N=30)\end{array}$} & \multicolumn{2}{|c|}{$\begin{array}{l}\text { Group rotary } \\
\qquad(\mathrm{N}=30)\end{array}$} & \multicolumn{2}{|c|}{$\begin{array}{c}\text { Total } \\
(\mathrm{N}=60)\end{array}$} & \\
\hline & $\mathbf{N}$ & $\%$ & $\mathbf{N}$ & $\%$ & $\mathbf{N}$ & $\%$ & \\
\hline $\begin{array}{c}\text { Acute } \\
\text { involvement }\end{array}$ & o & o & o & o & o & o & \multirow{4}{*}{0.45} \\
\hline $\begin{array}{c}\text { Chronic } \\
\text { involvement } \\
\end{array}$ & 25 & $83.3 \%$ & 27 & $90.0 \%$ & 52 & $86.7 \%$ & \\
\hline $\begin{array}{c}\text { Acute } \\
\text { exacerbation } \\
\text { of chronic } \\
\text { involvement }\end{array}$ & 5 & $16.7 \%$ & 3 & $10.0 \%$ & 8 & $13 \cdot 3 \%$ & \\
\hline Total & 30 & $100 \%$ & 30 & $100 \%$ & 60 & $100 \%$ & \\
\hline
\end{tabular}

Table 3. Duration of Onset of Pulpal Involvement in Teeth Indicated For Pulpectomy

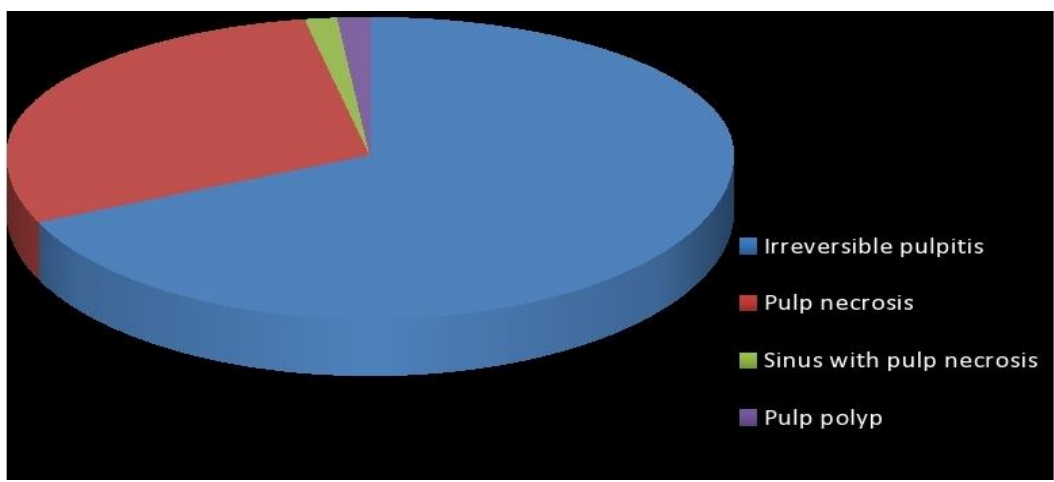

Figure 1. Indications for pulpectomy amongst the selected primary mandibular second molars

\section{DISCUSSION}

Pulpectomy is a routinely carried out clinical procedure in primary teeth and it was, therefore, possible to obtain an adequate sample. The advantage of carrying out this clinical trial in hospital-based population was to ensure the adequacy of the sample and an increased patient co-operation as they had themselves reported to the unit for treatment and was thus aware of the 


\begin{tabular}{|c|c|c|c|c|c|c|c|c|}
\hline \multicolumn{2}{|c|}{ Radiographic parameters } & $\mathbf{N}$ & $\%$ & $\mathbf{N}$ & $\%$ & $\mathbf{N}$ & $\%$ & P value \\
\hline \multicolumn{2}{|c|}{$\begin{array}{c}\text { No pre-operative } \\
\text { radiolucency }\end{array}$} & 26 & $86.7 \%$ & 27 & $90.0 \%$ & 53 & $88.3 \%$ & \multirow{4}{*}{0.69} \\
\hline \multirow{3}{*}{$\begin{array}{c}\text { Site of } \\
\text { radiolucency } \\
(\mathrm{N}=7) \\
\end{array}$} & Furcation area & o & o & o & o & o & o & \\
\hline & Periapical area & o & o & o & o & o & o & \\
\hline & Both & 4 & $57.1 \%$ & 3 & $42.9 \%$ & 7 & $100 \%$ & \\
\hline \multirow{2}{*}{$\begin{array}{l}\text { Root involved } \\
\text { in } \\
\text { radiolucency } \\
(\mathrm{N}=7)\end{array}$} & Mesial root & 1 & $14.28 \%$ & 1 & $14.28 \%$ & 2 & $28.6 \%$ & \multirow{2}{*}{0.91} \\
\hline & Distal root & 2 & $28.56 \%$ & 1 & $14.28 \%$ & 3 & $42.9 \%$ & \\
\hline $\begin{array}{l}\text { Size of } \\
\text { radiolucency } \\
(\mathrm{N}=7)\end{array}$ & more than $3 \mathrm{~mm}$ & 1 & $14.28 \%$ & o & o & 1 & $14.28 \%$ & 0.35 \\
\hline
\end{tabular}

Table 4. Preoperative Radiographic Characteristics of Primary Molars with Pulpectomy Indication

(Note: .a-Test is not applicable)

problem. The age range of 4-8 years was selected, as this age range could fulfill the presence of fully developed, unresorbed or minimally resorbed roots required for carrying out the endodontic treatment. The minimum age of 4 years was selected as primary mandibular second molars erupt into the oral cavity by the age of 2.5 to 3 years and a minimum time of $\mathbf{1 2 - 1 8}$ months is taken for a tooth to become carious and pulpally involved.6 The upper age limit was selected as 8 years to ensure that $2 / 3^{\text {rd }}$ of the root was present this is because normal exfoliation time for mandibular second primary molar ranges between 10-12 years.7 Children greater than 8 years of age were not included as the roots of primary mandibular second molars usually undergoes advanced physiological root resorption between 8-10 years. The primary mandibular second molars were selected as a sample tooth for the endodontic procedure to compare the manual and rotary method of root canal instrumentation as it is easy to carry out the treatment under direct vision in mandibular teeth compared to maxillary teeth. Moreover, primary mandibular second molars being a two-rooted tooth, the canals could be more precisely outlined in an intra-oral periapical radiograph (IOPA). Maxillary molars were not selected because of inherent problems of i)
Indirect vision ii) difficulty in visualizing the three roots of maxillary molars as these are not situated in the same plane. Also, generally the caries prevalence has been reported to be higher in mandibular primary teeth as compared to maxillary primary teeth.8,9,10,11 Primary mandibular first molars were not considered in the present study for the purpose of standardization.

On the evaluation of preoperative clinical parameters in the 4-8 year children in the two study groups, no statistically significant difference was observed with regards to pain, tenderness on percussion and sinus tract. Tenderness on percussion in the present study was limited to only one tooth $3.3 \%)$ in group rotary and none in group manual in contrast to studies like Mani et al. ${ }^{12}$ and Mathur et al. ${ }^{13}$ who reported tenderness on percussion at baseline in about $66 \%$ and $75 \%$ cases respectively. Similarly, only one tooth (3.3\%) from group manual showed the presence of a sinus tract at baseline and there was statistically no significant difference between the two study groups thus signifying that periradicular infection was not present in advanced stages in selected teeth as sinus formation is an indicator of the advanced stage of pulp and periradicular infection 
and can have impact on success of pulpectomy procedure. The pain was found to be the chief symptom with which majority of children reported for treatment as 18 subjects $(60 \%)$ in each of the two groups viz. group manual and group rotary had the history of pre-operative pain and there was no statistically significant difference between the two study groups. Rifkin ${ }^{14}$ in their study found that about $50 \%$ of the individuals who presented with carious exposed teeth had pain as the presenting symptom. However, Chawla HS et al. ${ }^{12}$ reported a pre-operative history of pain in about $88 \%$ of the cases. Teeth with mobility, abscess and those with intraoral or extraoral swelling were not included in the sample of the present study. The main indication for pulpectomy procedure in the total sample inclusive of the two groups was irreversible pulpitis (68.3\%) and pulp necrosis (28.3\%). Similar to the majority of studies in the literature including Chawla HS et al. ${ }^{13}$, Nadkarni and Damle $^{15,16}$ in the present study also irreversible pulpitis was the major cause for the inclusion of teeth for pulpectomy procedure followed by pulp necrosis.

An evaluation of radiographic parameters of the included teeth viz. 75,85 in the two study groups did not reveal any difference between the presence of radiolucency, site of radiolucency and size of radiolucency. A detailed radiographic analysis of the site of radiolucency revealed that both, as well as periapical areas, were involved in all the seven teeth with radiographic changes. This pattern of involvement of periapical or interradicular areas in primary teeth is different from that of permanent teeth, especially for the posterior ones. In permanent teeth, the usual site of involvement is periapical area compared to primary teeth where inter-radicular radiolucency is the first to develop followed by periapical area. Greater involvement of the furcation areas in primary mandibular second molars is due to less thickness of dentin and more number of accessory canals in the inter-radicular areas leading to a sieve-like pulpal floor which might be responsible for the early involvement of the furcation areas. ${ }^{17,18}$ Morabito and Dafabianis ${ }^{17}$ reported that $33 \%$ of maxillary and $85 \%$ of mandibular primary molars have aberrant canals in the pulpal floor. However, Wrabs et al. ${ }^{18}$ reported that $75 \%$ of primary mandibular molars had orifices of accessory canals in furcation areas, out of which 30\% were found to be patent. However, in the present study radiolucency at baseline was present in only $11.7 \%$ of the selected cases and all of which was seen in the furcation areas. A low prevalence of presence of radiolucency at baseline is possibly because of inclusion criteria where cases with abscess, abnormal mobility and swelling were not included, compared to studies showing a higher prevalence of radiolucency at baseline in the furcation areas where cases with abscess and swelling were included.

\section{CONCLUSION}

From the results, it can be concluded that the pain is the most common symptom for which pulpectomy treatment is carried out. Majority of cases show chronic involvement and irreversible pulpitis is the most common indication followed by pulp necrosis. Radiographic changes are less common in primary teeth indicated for pulpectomy although this finding may be confounded by selection criteria of the present study.

\section{REFERENCES}

1. Cohen S, Burns RC. Pediatric Endodontics: Endodontic Treatment for the Primary and Young Permanent Dentition. Pathway of the pulp. 1oth ed. St. Louis: Mosby Inc 2011;808.

2. Mc Donald RE, Avery DR. Dentistry for the child and adolescent. 7th ed. St. Louis: Mosby; Inc 2004. 3. Ruddle CJ. Cleaning and shaping the root canal system. In: Cohen S, Burns RC (eds). Pathways of the pulp. 8th ed. St. Louis: Mosby; Inc 2002;231292.

4. Glickman GN, Dumsha TC. Problems in canal cleaning and shaping. In: Gutmann JL, Dumsha TC, Lovdahl PE, Hovland EJ (eds). Problem solving in endodontics: prevention, identification, and management. 3th ed. St. Louise: Mosby; Inc 1997;91-121.

5. Eli I. Dental anxiety: A cause for possible misdiagnosis of tooth vitality. Int Endod J 1993:26: 251-53.

6. Finn SB. Child management in the dental office. In: Finn SB, editor. Clinical pedodontics. Philadelphia. WB saunders. 1998: pp39.

7. Finn SB. Morphology of primary teeth. In clinical pedodontics. $4^{\text {th }}$ Edition WB Saunders 
Co.1995.48.

8. Saravanan S, Madivanan I, Subashini B, Felix JW. Prevalence pattern of dental caries in the primary dentition among the school children.Indian Jour of Dent Res. 2005; 16:140-146. 9. Sathe PV. A textbook of Community Dentistry. $1^{\text {st }}$ edition Hyderabad, Paras medical publisher,1998.84-94.

10. Tewari A, Chawla HS. A study of prevalence of dental caries in an urban area of IndiaChandigarh. JIDA.1997; 49:231-237.

11. Jawdekar SL, Dandare MP, Maya Nato, Jawdekar SS. Dental caries susceptibility pattern. JIDA.1989; 60:200-203.

12. Chawla HS. Mani SA. Tewari A, Goyal A. Calcium hydroxide as a root canal filling material in primary teeth - a pilot study. J Indian Soc Pedo Prev Dent 1998; 6:3.

13. Chawla HS, Mathur VP, Gauba K, Goyal A. A mixture of $\mathrm{Ca}(\mathrm{OH})_{2}$ paste and $\mathrm{ZnO}$ powder as a root canal filling material for primary teeth: a preliminary study. J Indian Soc Pedo Prev Dent. 2001; 19:3. 107-109.

14. Rifkin A. A simple effective, safe technique for the root canal treatment of abscessed teeth. J Dent Child 1980; 47:435-441.

15. Nadkarni U, Damle S G. Comparative evaluation of calcium hydroxide and zinc oxide eugenol as root canal filling materials for primary molars: a clinical and radiographic study. J Indian Soc Pedod Prev Dent 2000;18:110.

16. Damle SG, Nadkarni UM. Calcium Hydroxide and Zinc Oxide Eugenol as root canal filling materials in primary molars: A comparative study. Aus Endo Journal. 2005; 3 (3).

17. Morabito A, Difabianis P. A SEM investigation on pulpal periodontal connections in primary teeth. J Dent Child 1992;59:53-57.

18. Wrabs KT, Kielbassa AM, Hellwig E. Microscopic studies of accessary canals in primary molars furcations. J Dent Child 1997;64:118-122.
Source of support: Nil, Conflict of interest: None declared

\section{Cite this article as:}

Morankar R, Goyal A. Clinical and Radiographic Characteristics of the Primary Teeth

Indicated For Pulpectomy: A Cross-Sectional Analysis. Int Healthc Res J. 2018;2(9):223-228. doi: 10.26440/ihrj.v2ig.182

\section{AUTHOR AFFILIATIONS:}

1. Assistant Professor,PGIMER Satellite Centre, Sangrur, Punjab

2. Professor, Unit of Pedodontics and Preventive Dentistry,Oral Health Sciences Centre,PGIMER, Chandigarh.

*Corresponding Author:

Dr. Rahul Morankar

Assistant Professor

PGIMER Satellite Centre

Sangrur

Punjab, India
For article enquiry/author contact details, e-mail at: editor.ihrj@gmail.com, editor@ihrjournal.com 